\title{
Frequency of Dengue virus Infection among Febrile Patients of Lahore
}

\author{
M.Salman Munir Malik ${ }^{1}$, Fahad javed ${ }^{2}$, M. Wasim² ${ }^{2}$, Maham Ulfat $^{1}$, Sana Arshad $^{1}$, \\ Rehmat Younas $^{2} \&$ Hafiz Ghulam Murtaza Saleem ${ }^{1}$ \\ ${ }^{1}$ UIMLT, The University of Lahore, Lahore, Pakistan \\ ${ }^{2}$ University of Health Sciences Lahore, Lahore, Pakistan \\ Correspondence: M.Salman Munir Malik ${ }^{1}$, University Institute of Medical Technology, The University of Lahore, \\ Lahore, Pakistan. Tel: 92-300-418-5997. E-mail: salmanawan48@yahoo.com
}

Received: July 4, 2017 Accepted: August 3, 2017 Online Published: September 20, 2017

doi:10.5539/gjhs.v9n10p212 URL: https://doi.org/10.5539/gjhs.v9n10p212

\begin{abstract}
Background: Dengue virus infection is one of the major global public health problems. The infection usually occurs with clinical manifestations ranging from an asymptomatic or mild febrile illness as classical dengue fever to the potentially life-threatening illness, dengue hemorrhagic fever and dengue shock syndrome. The objective of the current study was to observe the frequency and diagnosis of primary or secondary dengue viral infection among individuals in Lahore city, Pakistan.

Methods: Study subjects were identified for the presence of dengue diagnostic markers including NS1 antigen, IgM and IgG antibody. The dengue specific antigen NS1 was detected by immonochromatography, while dengue specific antibodies (IgM and IgG) were measured through ELISA.

Results: Total 98 (56\%) out of 175 febrile cases were found infected by dengue virus. From total 98 confirmed dengue cases, NS1 antigen was detected in $59(60.20 \%)$, IgM antibodies were present in $74(75.51 \%)$ and $\operatorname{IgG}$ antibodies were detected in $40(40.81 \%)$ individuals. Statistical analysis reveals correlation of NS1 antigen and IgM antibody among dengue patients with significant $\mathrm{P}$-value $(\mathrm{P}<0.01)$. Results indicated that $58(59 \%)$ were infected by primary infection and $40(41 \%)$ were infected by secondary infection. The most effected age group was $21-30$ years $(51.02 \%)$ and least effected age group was $<10$ years $(3.06 \%)$. Males were observed higher in number $61(62 \%)$ as compare to females $37(38 \%)$. Overall, the frequency of dengue virus infections were $56 \%$ among undifferentiated febrile patients in Lahore city, Pakistan.
\end{abstract}

Conclusion: Dengue is found endemic in city population with increased incidence in monsoon and post monsoon. Constant vigilance of patients and dengue vector control awareness programs among public and health care officials could support in combating dengue.

Keywords: dengue virus infection, febrile illness, hemorrhagic fever, immonochromatography

\section{Introduction}

Dengue fever is also known as bone break fever caused by dengue virus. Antigenically, comparable but different four serotypes of dengue virus can be transmitted to humans. Commonly found serotypes in Pakistan are DENV-2 and DENV-3, other types DENV-1 and DENV-4 are less common (Fatima et al., 2011). The genus of the virus in Flavivirus and family is Flaviviridae. Major source of dengue virus transmission is Aedes aegypti (A. aegypti) an arthropod (Murray, Quam, \& Wilder-Smith, 2013). A mosquito born viral infection know as dengue fever has spread rapidly all over the world. One half inhabitants of world are now at risk. Suitable climate for its vector is tropical and subtropical (Dupont-Rouzeyrol et al., 2015; Gubler, Ooi, Vasudevan, \& Farrar, 2014).The prevalence of dengue has been increased globally in recent decades. About 50-100 million people are infected by dengue every year and at least 25000 people are dead by this disease worldwide (Wilder-Smith \& Schwartz, 2005). Dengue is now an epidemic in more than 100 countries. First outbreak of dengue in the Pakistan have been reported in Karachi in 1994 (Humayoun, Waseem, Jawa, Hashmi, \& Akram, 2010; Khan et al., 2010; Qureshi, Notta, Salahuddin, Zaman, \& Khan, 1997). During 2005-2010 cases have been reported in Lahore, Karachi and some other cities (Fatima et al., 2011; Jamil, 2007; Tahir, Hafeez, \& Chaudhry, 2010). Dengue fever is well known disease in Pakistan after the huge outbreak of 2011 in Lahore (Ahmed et al., 2013). NS1 is a nonstructural protein of dengue virus released by infected cells. The NS1 antigen detection is very useful in recent dengue infection as it appears at the $1^{\text {st }}$ day or onset of fever and remains for nine to ten days. Different titters of NS1 can be detected 
each day $80 \%$ at day $1,60 \%$ at day 2 , and at day 4 and 5 it is $100 \%, 80 \%$ at day 6 is found positive. At day 7 and 9 NS1 is rarely seen and disappears at day 10 (Alcon et al., 2002). IgM antibodies are produced within the host against the virus and said to be the result of quick immune response against any infection. These antibodies appear after 3-4 days after the presence of symptoms of fever and decline gradually to invisible within 2-3 months (Gurugama, Garg, Perera, Wijewickrama, \& Seneviratne, 2010). IgM antibody detection can be useful for timely dengue infection diagnosis in primary stage while IgG antibodies are known as secondary immunoglobulins as they appear after the IgM.

The objective of the current study was to observe the frequency of dengue virus infection among individuals in Lahore city, Pakistan. That may help the clinician in the diagnosis of primary or secondary dengue infections and management of disease.

\section{Material and Methods}

\subsection{Study Design}

A retrospective study was conducted in Services Hospital Lahore (A tertiary care hospital) that based on the data of dengue suspected individuals visiting the hospital for one year from January 2016 to December 2016.

\subsection{Study Population}

The patients that visiting hospital with sign and symptoms and laboratory findings leading to dengue fever were included in this study. Study subjects were distributed in different six age groups to check the presence of dengue virus infection among different ages. Group distribution was as follows: Group 1 ( $<10$ years), group 2 (11-20 years), group 3 (21-30 years), group 4 (31-40 years), group 5 (41-50 years), group 6 ( $>50$ years). The venous blood samples were collected from patients. The selection of patients was according to the following criteria:

\subsection{Inclusion Criteria}

The patients with high fever, ocular pain, myalgia, headache, joint pain, hemorrhagic manifestations, abdominal pain and rashes with thrombocytopenia and deranged coagulation profile were selected for this study.

\subsection{Exclusion Criteria}

The patients with a known cause of fever were excluded from the study.

\subsection{Sample Size}

The number of samples in this study was 175 .

\subsection{Laboratory Analysis}

One-step qualitative assay of Dengue NS1 antigen was detected using rapid in vitro immunochromatographic test (ICT) kit by SD Bioline dengue NS1 antigen test. Test essay was performed according to the manufacturer's instructions. In each rapid test device about $100 \mu l$ of serum were added to the sample pad. These devices were then left undisturbed on a clean rigid shelf surface for 15-20 minutes. The chromogenic indicator in test devises produced a colored line in test strip as positive in response to the reaction. While the devices without line in test zone indicated negative reaction. In all devices, a colored line was also produced at control point for the purpose of device quality. Samples treated devices without control line were rejected and sample were repeated.

The IgM and IgG antibodies against dengue virus in human serum and plasma was identified using Dengue ELISA kit by Nova Tec. Test essay was performed according to the manufacturer's protocol. One hundred microliters of patient's serum and controls were added to their respective wells of microtiter plate. Then plate was incubated for 1 hour at $37^{\circ} \mathrm{C}$. Each well was washed thrice with $300 \mu l$ of washing solution. After washing $100 \mu l$ of dengue virus anti-IgM/ IgG conjugate was added into each well except the blank well. Washing was repeated and $100 \mu l$ of TMB substrate solution was added into each wells. To stop the reaction, $100 \mu l$ of stop solution was then added to each well. Microtiter plate reader was used to measure the absorbance at $450 \mathrm{~nm}$. Mean absorbance value of triplicate was calculated.

\subsection{Statistical Analysis}

It was also performed with correlation test using SPSS 21 to find the significant P-value.

\section{Results}

Total 175 samples were collected from febrile patients and tested for the detection of dengue diagnostic markers including $\operatorname{IgM} / \mathrm{IgG}$ antibodies and NS1 antigen. Patient were diagnosed with the presence of antibody type against dengue virus as IgM with primary dengue infection and IgG with secondary dengue infection. Total 98 (56\%) out of 175 individuals were found infected by dengue virus and 77 (44\%) individuals were absent for dengue antigen 
and antibodies as shown in Table 1. Forty (40) out of 98 suspected individuals were suffering from recent primary infection and 18 were carrying primary infection. Recent secondary infection was present in 4 individuals and 17 individuals were infected with secondary infection. The results indicated that 19 individuals were infected by the dengue virus for the second time or they were suffering from recent secondary infection.

Table 1. Distribution of confirm dengue cases with different stages of dengue and non-dengue febrile cases

\begin{tabular}{|c|c|c|c|c|c|}
\hline \multicolumn{6}{|c|}{ Result interpretation of dengue diagnostic parameters } \\
\hline Serial No. & NS1 & IgM & IgG & Interpretation & No. of cases $(\%)$ \\
\hline 1 & + & - & - & Recent primary infection & $7(7.14)$ \\
\hline 2 & + & + & - & Recent primary infection & $33(33.67)$ \\
\hline 3 & - & + & - & Primary infection & $18(18.36)$ \\
\hline 4 & - & + & + & Recent secondary infection & $4(4.08)$ \\
\hline 5 & - & - & + & Secondary infection & $17(17.34)$ \\
\hline \multirow[t]{2}{*}{6} & + & + & + & $2^{\text {nd }}$ exposure of infection or recent secondary infection & $19(19.38)$ \\
\hline & & & & Total confirmed dengue cases & $98(56)$ \\
\hline 7 & - & - & - & Unknown febrile infection & $77(44)$ \\
\hline \multicolumn{5}{|c|}{ Total no. of suspected individuals } & 175 \\
\hline
\end{tabular}

Table 2 showed the age and gender wise distribution of confirmed dengue cases. The highest $50(51.02 \%)$ number of individuals were present in age group 3 followed by 18 from age group 2, 16 from age group 4, 6 from age group 5,5 from age group 6 and 3 individuals were confirmed for dengue virus infection from age group 1. Sixty one (61) were males and $37(38 \%)$ were females from total 98 confirmed dengue cases where NS1 antigen was detected in $59(60.20 \%)$ individuals, IgM antibodies were present in $74(75.51 \%)$ and $\operatorname{IgG}$ antibodies were noticed in 40 (40.81\%).

Table 2. Age-wise distribution of confirm dengue cases with dengue diagnostic parameters

\begin{tabular}{llllll}
\hline \multirow{2}{*}{ Age group } & Female & Male & NS-1 & IgM & IgG \\
\cline { 2 - 6 } & No. (\%) & No. (\%) & No. of cases (\%) & No. of cases (\%) & No. of cases (\%) \\
\hline 1 & 0 & $3(3.06)$ & $1(1.02)$ & $3(3.06)$ & $1(1.02)$ \\
2 & $12(12.24)$ & $6(6.12)$ & $6(6.12)$ & $12(12.24)$ & $7(7.14)$ \\
3 & $18(18.36)$ & $32(32.65)$ & $36(36.73)$ & $36(36.73)$ & $20(20.40)$ \\
4 & 6() & $10(10.20)$ & $10(10.20)$ & $15(15.30)$ & $6(6.12)$ \\
5 & $1(1.02)$ & $5(5.10)$ & $5(5.10)$ & $5(5.10)$ & $2(2.04)$ \\
6 & 0 & $5(5.10)$ & $1(1.02)$ & $3(3.06)$ & $4(4.08)$ \\
Total confirmed cases & $37(37.75)$ & $61(62.24)$ & $59(60.20)$ & $74(75.51)$ & $40(40.81)$ \\
\hline
\end{tabular}

Statistical results indicated the correlation of NS1 antigen and IgM antibody among dengue patients with significant $\mathrm{P}$-value $(\mathrm{P}<0.01)$.

\section{Discussion}

This study was conducted to detect the NS1 antigen, IgG and, IgM antibodies against dengue virus in blood of dengue suspected individuals. The study showed that $56 \%$ of 175 individuals were found infected by dengue fever and other 77 (44\%) individuals were suffering from some other disease. This number of confirmed cases was higher than the cases reported from other countries like India, Pacific Islands and Brazil. During 2006 to 2010 in India $19.7 \%$ positivity of dengue was reported, highest $46.5 \%$ positivity during this period was found in 2010 . In 2012 in pacific islands 4\% people were infected by dengue and during FIFA world cup events in Brazil in 2014 rate of dengue virus infection was 31\%, report was published in 2015 (Garg, Garg, Rao, Upadhyay, \& Sakhuja, 2011; 
M. E. Wilson \& Chen, 2015). In 2008, Institute of public health sciences reported the geographical distribution of dengue fever and the overall number of confirmed dengue patients was closely similar to present study $54.94 \%$ (Tahir et al., 2010). It was noticed in this study that 40 patients were carrying recent primary infection followed by 18 patients were carrying primary infection, 4 patients were with recent secondary infection and 18 patients were suffering with secondary infection of dengue virus. NS-1 positive patients were considered as recently infected, IgM positive patients with primary infection and IgG positive patients were considered as carrying a secondary infection (Sa-Ngasang et al., 2006). Current study showed that 18 patients were having recent secondary infection or they were infected by dengue virus for the second time because all three diagnostic markers like NS1 antigen, $\mathrm{IgM}$ and $\mathrm{IgG}$ antibodies were present in their blood.

Dengue virus can infect individuals of any age worldwide (Gubler, 1998). People of different ages were tested for the detection of dengue virus infection in this study, the highest (50) number of individuals were confirmed for dengue virus infection from the age group 21-30 years. The lowest number (3) of confirmed dengue cases was from the age group $<10$ years, followed by 5 confirmed dengue cases from the age group $>50$ years. In this study age wise distribution showed the involvement of all age groups with significant number in adults of 21-30 years in comparison to children and people above 50 years of age. Other countries of south Asia also showed similar findings of infection in same age group 21-30 years (Chakravarti \& Kumaria, 2005). Age group 21-30 years was also seen prominent in some previous studies in India. Ekta Gupta in 2006 from India reported that the highest frequency of dengue infection was seen in age group 21-30 years during 2003-2005 (Gupta, Dar, Kapoor, \& Broor, 2006). In 2009, from Lahore Pakistan the highest number of suspected individuals was seen in age group of 16-30 years showed similarity with present study (Mahmood, Jameel, Aslam, \& Tahir, 2009). Dengue virus was reported as endemic in Pakistan throughout the year and most cases was found in monsoon period (Khan et al., 2010). The median age of dengue virus infected individuals have been discovered in this study as young adults. A study reported in 2010 that the prevalence of dengue has been seen in the adults from the age group 20-45 years (Hakim, Tayyab, \& Nadeem, 2011). A report from Kenya in 2014 indicated the involvement of the people from age group 26-35 years for carrying dengue virus infection and the reason was said to be the involvement of the people from this age group to the activities that increase the chances of exposure to the A. aegyptie during working (Mulati, 2014).It was also observed from current study that $62 \%$ males and $38 \%$ females from confirmed dengue cases were infected with virus. Previous study reported that males are said to be more prone to dengue infection because they are working outside as compare to females living inside their homes in Pakistan (Humayoun et al., 2010). Another study also reported in 2010 that the females are less prone to dengue virus infection than males (Hakim et al., 2011). In 2014, study reported $79 \%$ males and $21 \%$ females infected by dengue virus infection in different cities of Pakistan during the year of 2010 (Munir et al., 2014). During this study, the NS1 antigen were found in the blood samples of 59 individuals that confirmed them as infected by dengue virus. This study showed $60.20 \%$ presence of NS1 dengue antigen in patient blood. The presence of a high number of NS1 means that $60.20 \%$ cases were diagnosed in early stages of the fever. Because NS1 antigen can be found in blood of infected patients at the first day of onset of fever till approximately 10 days, the highest titer of NS1 can be detected between day 2 to day 4 (Alcon et al., 2002). The frequency of IgM antibodies was higher than both the frequency of NS1 antigen and the frequency of $\operatorname{IgG}$ antibodies in the recent study. The detection of $\operatorname{IgM}$ antibodies was observed higher $75 \%$ of confirmed 98 dengue infected patients in comparison with other study having $\operatorname{IgM} 48.7 \%$ and $\operatorname{IgG} 39.5 \%$ from Pakistan in 2009. (Mahmood et al., 2009). IgM antibodies are said to be the result of quick immune response against any infection. These antibodies appear after 3-4 days after the onset of fever and decline gradually to undetectable within 2-3 months (Guzman et al., 2010; J. D. Wilson \& Simpson, 2012). IgG antibodies were detected in $40.81 \%$ of dengue infected confirmed patients. In present study the frequency of IgG antibodies was observed low in number in comparison with IgM antibodies and NS1 antigen and it was similar to previous study reported $63 \% \operatorname{IgM}$ and $42 \%$ IgG antibody (Hakim et al., 2011). IgG antibodies are known as secondary immunoglobulins as they come after the IgM. IgG antibodies start appearing at the end of first week. The presence of NS1 and IgM is seen directly proportional while the presence of IgG and NS1 is inversely proportional as the detection of NS1 decrease with the increase of IgG. Another study also reported that the rate of NS1 detection is inversely proportional to the presence of $\operatorname{IgG}$ while IgM detection rate is directly proportional to NS1 (Wang \& Sekaran, 2010).

\section{Conclusion}

Timely detection of NS1 antigen, IgM and IgG antibodies may be useful for the diagnosis of patients, early identification of patients at risk of hemorrhage and dengue management. Dengue is endemic in city population with increased incidence in monsoon and post monsoon. Constant vigilance of patients with isolation in hospital wards and dengue vector control awareness programs among public and health care officials could support in 
combating dengue.

\section{Author's Contribution}

MSM accomplished the statistical analysis and compose the manuscript, FJ and MW did sampling and design the study, MU, SA and RY did lab work and recruitment of the patients HGMS did the final revision of manuscript.

\section{Competing Interests Statement}

There is no conflict of interest among authors

\section{References}

Ahmed, S., Mohammad, W. W., Hamid, F., Akhter, A., Afzal, R. K., \& Mahmood, A. (2013). The 2011 dengue haemorrhagic fever outbreak in Lahore-an account of clinical parameters and pattern of haemorrhagic complications. J Coll Physicians Surg Pak, 23(7), 463-467.

Alcon, S., Talarmin, A., Debruyne, M., Falconar, A., Deubel, V., \& Flamand, M. (2002). Enzyme-linked immunosorbent assay specific to Dengue virus type 1 nonstructural protein NS1 reveals circulation of the antigen in the blood during the acute phase of disease in patients experiencing primary or secondary infections. Journal of clinical microbiology, 40(2), 376-381. https://doi.org/10.1128/JCM.40.02.376-381.2002

Chakravarti, A., \& Kumaria, R. (2005). Eco-epidemiological analysis of dengue infection during an outbreak of dengue fever, India. Virology journal, 2(1), 32. https://doi.org/10.1186/1743-422X-2-32

Dupont-Rouzeyrol, M., O’Connor, O., Calvez, E., Daures, M., John, M., Grangeon, J.-P., \& Gourinat, A.-C. (2015) Co-infection with Zika and dengue viruses in 2 patients, New Caledonia, 2014. Emerging infectious diseases, 21(2), 381. https://doi.org/10.3201/eid2102.141553

Fatima, Z., Idrees, M., Bajwa, M. A., Tahir, Z., Ullah, O., Zia, M. Q., . . Afzal, S. (2011). Serotype and genotype analysis of dengue virus by sequencing followed by phylogenetic analysis using samples from three mini outbreaks-2007-2009 in Pakistan. BMC microbiology, 11(1), 200. https://doi.org/10.1186/1471-2180-11-200

Garg, A., Garg, J., Rao, Y., Upadhyay, G., \& Sakhuja, S. (2011). Prevalence of dengue among clinically suspected febrile episodes at a teaching hospital in North India. Journal of Infectious Diseases and Immunity, 3(5), 85-89.

Gubler, D. J. (1998). Dengue and dengue hemorrhagic fever. Clinical microbiology reviews, 11(3), 480-496.

Gubler, D. J., Ooi, E. E., Vasudevan, S., \& Farrar, J. (2014). Dengue and dengue hemorrhagic fever: CABI.

Gupta, E., Dar, L., Kapoor, G., \& Broor, S. (2006). The changing epidemiology of dengue in Delhi, India. Virology journal, 3(1), 92. https://doi.org/10.1186/1743-422X-3-92

Gurugama, P., Garg, P., Perera, J., Wijewickrama, A., \& Seneviratne, S. L. (2010). Dengue viral infections. Indian journal of dermatology, 55(1), 68. https://doi.org/10.4103/0019-5154.60357

Guzman, M. G., Halstead, S. B., Artsob, H., Buchy, P., Farrar, J., Gubler, D. J., . . Martínez, E. (2010). Dengue: a continuing global threat. Nature Reviews Microbiology, 8, S7-S16. https://doi.org/10.1038/nrmicro2460

Hakim, S. T., Tayyab, S. M. H., \& Nadeem, S. G. (2011). An experience with dengue in Pakistan: An expanding problem. Ibnosina Journal of Medicine and Biomedical Sciences, 3(1), 3-8. https://doi.org/10.4103/1947-489X.210848

Humayoun, M. A., Waseem, T., Jawa, A. A., Hashmi, M. S., \& Akram, J. (2010). Multiple dengue serotypes and high frequency of dengue hemorrhagic fever at two tertiary care hospitals in Lahore during the 2008 dengue virus outbreak in Punjab, Pakistan. International Journal of Infectious Diseases, 14, e54-e59. https://doi.org/10.1016/j.ijid.2009.10.008

Jamil, B. (2007). Dengue Virus Serotype 3, Karachi, Pakistan-Volume 13, Number 1-January 2007-Emerging Infectious Disease journal-CDC.

Khan, E., Kisat, M., Khan, N., Nasir, A., Ayub, S., \& Hasan, R. (2010). Demographic and clinical features of dengue fever in Pakistan from 2003-2007: a retrospective cross-sectional study. PloS one, 5(9), e12505. https://doi.org/10.1371/journal.pone.0012505

Mahmood, K., Jameel, T., Aslam, H. F., \& Tahir, M. (2009). Incidence of dengue haemorrhagic fever in local population of Lahore, Pakistan. Biomedica, 25(3), 93-96.

Mulati, O. K. (2014). Prevalence of dengue viral infections among febrile patients in Mombasa County, Kenya. 
Kenyatta University.

Munir, M. A., Alam, S. E., Khan, Z. U., Saeed, Q., Arif, A., Iqbal, R., . . Qureshi, H. (2014). Dengue fever in patients admitted in tertiary care hospitals in Pakistan. JPMA, 64(553).

Murray, N. E. A., Quam, M. B., \& Wilder-Smith, A. (2013). Epidemiology of dengue: past, present and future prospects.

Qureshi, J. A., Notta, N., Salahuddin, N., Zaman, V., \& Khan, J. (1997). An epidemic of Dengue fever in Karachi--associated clinical manifestations. JPMA. The Journal of the Pakistan Medical Association, 47(7), 178-181.

Sa-Ngasang, A., Anantapreecha, S., A-nuegoonpipat, A., Chanama, S., Wibulwattanakij, S., Pattanakul, K., .. . Kurane, I. (2006). Specific IgM and IgG responses in primary and secondary dengue virus infections determined by enzyme-linked immunosorbent assay. Epidemiology and infection, 134(04), 820-825. https://doi.org/10.1017/S0950268805005753

Tahir, Z., Hafeez, S., \& Chaudhry, A. (2010). Spatial and seasonal variation of dengue fever in Lahore 2008. Biomedica, 26, 166-172.

Wang, S. M., \& Sekaran, S. D. (2010). Early diagnosis of Dengue infection using a commercial Dengue Duo rapid test kit for the detection of NS1, IGM, and IGG. The American journal of tropical medicine and hygiene, 83(3), 690-695. https://doi.org/10.4269/ajtmh.2010.10-0117

Wilder-Smith, A., \& Schwartz, E. (2005). Dengue in travelers. New England Journal of Medicine, 353(9), 924-932. https://doi.org/10.1056/NEJMra041927

Wilson, J. D., \& Simpson, S. I. (2012). Diagnostic Immunology and Serology: A Clinicians' Guide: Springer Science \& Business Media.

Wilson, M. E., \& Chen, L. H. (2015). Dengue: update on epidemiology. Current infectious disease reports, 17(1), 457. https://doi.org/10.1007/s11908-014-0457-2

\section{Copyrights}

Copyright for this article is retained by the author(s), with first publication rights granted to the journal.

This is an open-access article distributed under the terms and conditions of the Creative Commons Attribution license (http://creativecommons.org/licenses/by/4.0/). 